\title{
Positive humor in couples as interpersonal emotion regulation: A dyadic study in everyday life on the mediating role of psychological intimacy
}

Journal of Social and Personal Relationships

|-2 |

(C) The Author(s) 2018 Article reuse guidelines: sagepub.com/journals-permissions DOI: $10.1 \mid$ 177/02654075|8788|97 journals.sagepub.com/home/spr @SAGE

\author{
Andrea B. Horn $\mathbb{1}^{1}$, Andrea C. Samson ${ }^{2,3}$, Anik Debrot ${ }^{4}$, \\ and Meinrad Perrez
}

\begin{abstract}
The aim of this study was to investigate daily positive humor in couples as an interpersonal emotion regulation strategy. Associated changes in psychological intimacy were tested as a possible socio-affective pathway of emotion regulation that mediates the effects of couple humor on changes in individual momentary affect. Within a dyadic ambulatory assessment framework, 102 couples reported on their production of positive humor as an attempt to regulate their partner's mood, psychological intimacy, and momentary affect four times a day for I week. An actor-partner interdependence mediation model revealed actor and partner effects of humor on changes in daily affect. Furthermore, the indirect effect of own humor via changes in the partner's feelings of psychological intimacy (socio-affective pathway) on the partner's affect was significant. Results support the assumption that daily positive humor experienced with one's romantic partner serves as an interpersonal emotion regulation strategy in daily life as
\end{abstract}

\footnotetext{
1 University of Zurich, Switzerland

2 University of Geneva, Switzerland

${ }^{3}$ Swiss Distance Learning University, Switzerland

${ }^{4}$ University of Lausanne, Switzerland

${ }^{5}$ University of Fribourg, Switzerland
}

Corresponding author:

Andrea B. Horn, "CoupleSense: Health and Interpersonal Emotion Regulation" Group, University Research Priority Program "Dynamics of Healthy Aging," University of Zurich, Andreasstrasse 15/2, 8050 Zürich, Switzerland.

Email: a.horn@psychologie.uzh.ch 
reflected in direct effects on one's own and one's partner's momentary affect. The partner's changes in affect were partially mediated by changes in their feelings of psychological intimacy. This speaks in favor of an indirect socio-affective mechanism of interpersonal emotion regulation associated with positive humor expressed toward the partner.

\section{Keywords}

Couple, interpersonal emotion regulation, intimacy, momentary affect, positive humor, socio-affective pathway

Positive social interactions are essential to health and well-being (Holt-Lunstad \& Smith, 2012; Holt-Lunstad, Smith, Baker, Harris, \& Stephenson, 2015). Accordingly, research shows that laughter is linked to improved individual health and well-being (Maiolino \& Kuiper, 2016; Martin, 2002), especially shared laughter with close others (Martin, 2004). Moreover, positive humor in relational contexts has the potential to increase relationship satisfaction (see Hall, 2017).

However, less is known about the pathway by which humor affects changes in wellbeing when it is used in couples' daily life. In the present study, we aimed to investigate whether the production of positive humor is associated with changes in emotional wellbeing in daily life of both individuals and their romantic partners. Moreover, we examined the possible mediating role of psychological intimacy in the relationship between humor and daily affective experience. The theoretical framework integrates research on positive humor and relationship processes with recent developments suggesting an interpersonal view on emotion regulation. Our underlying assumption is that humor-induced changes in relationship quality may serve a regulatory purpose for both partners. To test this hypothesis, we developed an intensive longitudinal dyadic study design in which members of a romantic dyad were asked to respond individually to queries, four times a day for the duration of a week.

\section{Humor as an emotion regulation strategy}

Humor has long been seen as an adaptive way to cope with adversity, ranging from everyday life hassles to major negative life events (Freud, 1928; Vaillant, 1992). More specifically, recent research suggests an emotion regulatory function of humor (BoothButterfield, Wanzer, Weil, \& Krezmien, 2014; Goldin, McRae, Ramel, \& Gross, 2008; Samson, Glassco, Lee, \& Gross, 2014; Vela, Booth-Butterfield, Wanzer, \& Vallade, 2013). Emotion regulation has been defined as the heterogeneous set of processes by which emotions are influenced (i.e., dampening, intensifying, maintaining, installing, or ending an emotion; Gross \& Thompson, 2007).

In recent research, several mechanisms have been suggested to explain the function of humor as an emotion regulation strategy. Humor can distract away from negative emotions (Strick, Holland, van Baaren, \& Van Knippenberg, 2009), and it can "undo" negative emotions by eliciting positive emotions (Fredrickson \& Levenson, 1998); 
humor can change the perspective on a negative event, which ultimately has the potential to alter its emotional impact (i.e., reappraisal mechanism; Kugler \& Kuhbandner, 2015; Samson \& Gross, 2012, 2014). It is important to specify that these adaptive emotion regulatory effects are stronger for the use of positive humor (i.e., good-natured, benevolent, and integrating), compared to negative humor (i.e., mean-spirited, disparaging, hostile, or aggressive; Samson \& Gross, 2012). Moreover, correlational research on selfenhancing humor, a positive intrapersonal humor style as compared to self-deprecating humor, a negative intrapersonal humor style, showed that only the positive humor style is related to beneficial outcomes (Martin, Puhlik-Doris, Larsen, Gray, \& Weir, 2003).

\section{Humor in romantic relationships: Improving relationship quality}

A further line of research focuses on the potential relational consequences of humor. Several attempts have been made to understand the role of humor in social interactions (e.g., Martin, 2004). Humor has various relational functions, including the potential to support interpersonal emotion regulation. In interpersonal interactions, there is also a distinction between positive (e.g., affiliative humor) and negative types or styles of humor (e.g., aggressive or hostile humor; Martin, 2004). Findings from the intrapersonal domain, including social contexts, suggest that positive styles of humor have an adaptive effect on the relationship (Cann, Zapata, \& Davis, 2009; Hall, 2013), whereas hostile and aggressive humor styles have a negative effect (Hall, 2017).

Despite the important advances of relationship science in the last decades, it is still not fully understood how processes in close relationships promote well-being in individuals and relationships, and which mechanisms explain this association (Pietromonaco \& Collins, 2017). Aiming to better understand relevant processes mediating adaptive effects of relationships on individual and relational well-being, the focus of the present research is to investigate the association between the expression of daily positive humor in romantic relationships with individual and relationship outcomes. As the study is embedded in an emotion regulatory framework, positive humor is assessed as an extrinsic interpersonal emotion regulation strategy. Interpersonal emotion regulation is broadly defined as emotion regulation taking place in social interaction with possible effects on one's own and one's partner's affective state (Horn \& Maercker, 2016). More specifically, extrinsic interpersonal emotion regulation has been defined as regulation strategies employed to regulate the emotions of others (Gross \& Thompson, 2007) and can be considered as one form of interpersonal emotion regulation. Accordingly, in this study, the production of positive humor was assessed in the context of a benevolent attempt to regulate the partner's daily affect. The wording of the item used to gage interpersonal emotion regulation in our study was "when dealing with my partner's current mood, I tried to bring in good humor."

The notion of interpersonal regulatory functions of humor in the relationship context is informed by research providing strong evidence that humor also serves relational functions in couple relationships (Booth-Butterfield et al., 2014; Hall, 2017). In fact, positive forms of humor are often reported as a critical component of successful romantic relationships (Hall, 2017; Lauer, Lauer, \& Kerr, 1990) and have been associated with 
improved relationship quality. For example, a study by Howland and Simpson (2014), using an observed interaction framework, demonstrated that individuals using humor were more empathically accurate and responsive toward their romantic partner-a mechanism linked to relationship quality. Moreover, the use of affiliative humor (i.e., a form of positive humor that is aimed at enhancing relationships) was associated with a decrease in partners' negative affect in this study. In further studies relying on questionnaires and coding of social interactions, affiliative humor was associated with more closeness and more effective conflict resolution in couples (Campbell, Martin, \& Ward, 2008; Winterheld, Simpson, \& Oriña, 2013). For instance, De Koning and Weiss (2002) showed that the use of positive humor was correlated with a person's own relationship satisfaction, but only in wives. However, positive humor was associated with the partner's intimacy and relationship satisfaction in both husbands and wives. The finding of positive partner effects is in line with recent research pointing to the possible coregulatory function of individuals' use of humor in social interactions as a method of coping with stressful situations such as bereavement (Booth-Butterfield et al., 2014).

As soon as humor is displayed in the company of others, the common enjoyment of the humorous moment becomes increasingly important. Accordingly, shared laughter has been introduced as a behavioral indicator of relational well-being (Kurtz \& Algoe, 2015). A 2-week experience sampling study investigating shared laughter with different interaction partners revealed that shared laughter is associated with better relationship quality with the interaction partner and more positive affect in the individual (Kashdan, Yarbro, McKnight, \& Nezlek, 2014).

There is evidence that the reported between-person associations regarding positive forms of humor are also reflected on a within-person level in daily life. A diary study showed that individuals were more satisfied with their relationships when they reported higher levels of affiliative humor, while other humor styles did not make a difference (Caird \& Martin, 2014). However, a limitation of this study was that it only included single-person perspectives and dyadic analyses were not performed. Therefore, interdependencies between partners and humor effects crossing over to the partner could not be investigated.

With regard to relational processes, there is a need for dyadic study designs that allow us to capture the interplay between one's own and the partner's behavior (Kenny, Cashy, $\&$ Cook, 2006). Such study designs are increasingly used in the research field of relational humor. A recent meta-analysis by Hall (2017) reveals that the effect of the partner's report of positive relational humor on relationship quality above and beyond one's own use of humor showed medium effect sizes, which is comparable to actor effects (i.e., the effect of own humor on own relationship quality). The same metaanalysis revealed weak associations with the partner's satisfaction of more selfdirected and negative types of humor. Linked to this, when conflict situations are induced in the lab, partner effects of affiliative humor are even larger than the actor effects (i.e., partners benefitted more from affiliative humor than the joker; Campbell et al., 2008).

However, in the current literature, little is known about the relationship between a person's own humor and their partner's humor in daily life. As an attempt to fill this gap in dyadic humor research, a dyadic intensive longitudinal framework will be developed 


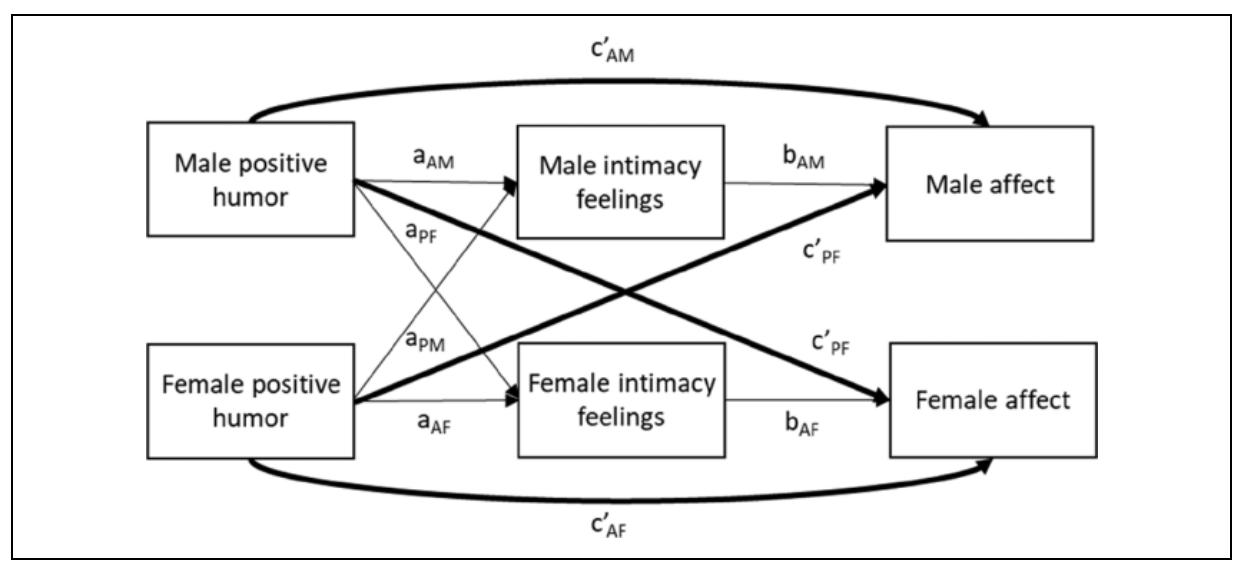

Figure I. Conceptual model for the multilevel actor-partner mediation model. Indirect actor mediation path via own intimacy: $a_{A M}-b_{A M} / a_{A F}-b_{A F}$; indirect partner mediation path via partner intimacy: $a_{P M}-b_{A M} / a_{P M}-b_{A F} . a=$ First mediational path; $b=$ second mediational path; $c^{\prime}=$ direct effect (bold); $A=$ actor; $P=$ partner; $M=$ male; and $F=$ female.

and applied in the current study, allowing us to assess changes in daily well-being and relationship quality on both romantic partners and investigate associations with daily positive humor.

\section{The socio-affective pathway: Humor as an interpersonal emotion regulation strategy}

In sum, positive humor as displayed in social interactions has a beneficial impact on individually experienced affect as well as on relational characteristics associated with improved relationship quality. Fraley and Aron (2004) suggested that besides shared enjoyment, humorous interactions promote disclosure and responsiveness, which are known to be essential for the establishment of psychological intimacy (Reis \& Shaver, 1988). Psychological intimacy, in turn, can be seen as the core mechanism underlying features of relationship quality, like marital satisfaction or relationship distress. Considering the abovementioned, it can be argued that in relational contexts, humor does not only regulate the individual's emotions via intrapersonal processes such as distraction, an "undoing" effect on negative emotions, and certain kinds of reappraisal (Samson \& Gross, 2012) but also via changes in interpersonal mechanisms. More specifically, in line with current interpersonal perspectives on emotion regulation (Coan \& Sbarra, 2015), it can be hypothesized that changes in psychological intimacy are a mechanism by which emotions are regulated in the social context. Accordingly, in the current study, we did investigate whether known associations between positive humor and improved relationship quality represent a pathway to more positive affect, which in turn serves an emotion regulatory purpose. The conceptual model describing this framework is depicted in Figure 1. Paths $\mathrm{c}_{\mathrm{AM}}$ and $\mathrm{c}_{\mathrm{AF}}$ are used to represent the direct connection 
between humor and affect, that is, the male $\left(c_{\mathrm{AM}}\right)$ and female $\left(c_{\mathrm{AF}}\right)$ actor effect, as outlined in the first section of the introduction (see $c$ ). Paths represented with the letter $a$ are informed by the known actor and partner effects of positive humor on different aspects of relationship quality as described earlier. Finally, the following paragraph is dedicated to introducing the theoretical framework informing the suggested $b$ paths, between feelings of psychological intimacy and affect.

Recent views on interpersonal emotion regulation put great emphasis on the regulative nature of relationship quality indicators such as social proximity (Coan \& Sbarra, 2015) or social connections (Kok et al., 2013; Rime, 2007). These approaches view changes in the social context as being regulatory in themselves. The social baseline theory (Coan \& Sbarra, 2015) postulates that feelings of closeness in relationships signal a safe and predictable environment leading to reduced emotional reactions and deactivated neural self-regulation networks (Coan et al., 2017; Coan, Schaefer, \& Davidson, 2006). Further elaborating on the interpersonal view of emotion regulation, it has been suggested that, in daily life, verbal and nonverbal relational behaviors that foster psychological intimacy, a core process underlying relationship quality, might nurture a socio-affective pathway that can be seen as reflecting a genuine interpersonal, indirect path of emotion regulation (Debrot, Schoebi, Perrez, \& Horn, 2013). This path does not work by known intrapersonal mechanisms such as reappraisal or distraction but rather works indirectly through changes in the perceived relationship quality in the current social environment, which in turn leads to more positive affect.

\section{The present study}

In this study, positive humor produced in daily life as a response to the partner's affective states was investigated as an interpersonal emotion regulation strategy in a dyadic ambulatory assessment study. Actor and partner effects of positive humor were studied with both partners of romantic couples to examine if there is an increase in an individual's positive affect when their partner reports using more positive humor (partner effects; extrinsic interpersonal emotion regulation) above and beyond the individual's own production of positive humor (actor effects). Most importantly, the current study aimed to understand if the effects of positive humor on the partner's affective states are mediated by increases in psychological intimacy.

In other words, the following was hypothesized.

H1: In daily life, in the hours succeeding displays of positive humor, there will be an increase in affective valence in the individual displaying positive humor (actor effect see, Figure 1, paths $c_{\mathrm{pm} / \mathrm{pf}}^{\prime}$ ), as well as in their partner (partner effect; see Figure 1, paths $c^{\prime}{ }_{\mathrm{pm} / \mathrm{pf}}$ ).

H2: In daily life, in the hours succeeding displays of positive humor, there will be an increase in psychological intimacy in the individual displaying positive humor (actor effect, see Figure 1, paths $a_{\mathrm{am} / \mathrm{af}}$ ), as well as in their partner (partner effect; Figure 1, paths $a_{\mathrm{pm} / \mathrm{pf}}$ ). 
H3: There will be indirect effects on increases in positive affective valence of an individual's own humor through changes in a person's own intimacy (actor mediation, see Figure 1, paths $a_{\mathrm{AM}}-b_{\mathrm{AM}} / a_{\mathrm{AF}}-b_{\mathrm{AF}}$ ), respectively, through changes in their partner's intimacy (partner mediation, see Figure 1, paths $\left.a_{\mathrm{AM}}-b_{\mathrm{AM}} / a_{\mathrm{AF}}-b_{\mathrm{AF}}\right)$.

\section{Method}

\section{Participants}

One hundred and two participating couples met our study's inclusion criteria of being between the ages of 18 and 40 years, being in a committed relationship for at least 3 months, and seeing each other regularly (at least three times a week). A total of 102 couples were included in the study. The sample size was decided in advance allowing us to answer the abovementioned research questions with sufficient statistical power (Bolger, Stadler, \& Laurenceau, 2012; Maas \& Hox, 2005). Couples were recruited via e-mails sent to college students in Swiss colleges and universities and via media reports in local newspapers. Participants' mean age was 25.40 years $(S D=5.08)$. The couples' mean relationship duration was approximately 3 years $(M=35.48$ months, $S D=32.31$, ranging from 4 to 180$)$, and $43.3 \%$ of the couples were cohabitating. The majority $(90 \%)$ indicated that they regularly slept in the same room, including those living in separate apartments. In terms of their education level, most participants reported having completed high school $(89.8 \%$ ), and $27 \%$ of participants had a master's degree. The study population consisted partly of college students (54.4\%) and partly of employed individuals (45.6\%). The couples' average relationship satisfaction, as measured by the German version of the Relationship Assessment Scale (Dinkel \& Balck, 2005; Hendrick, Dicke, \& Hendrick, 1998), was high ( $M=30.97$, with a range of scores between $16=$ very unsatisfied and $35=$ very satisfied).

\section{Procedure}

The procedure was approved by the ethics committee for research with human participants of the German Association of Psychology (Deutsche Gesellschaft für Psychologie). After indicating interest in taking part in the study, prospective participants were contacted by phone or via e-mail to determine whether they met all inclusion criteria. After providing their informed consent, couples were asked to choose an assessment week that would be representative of their daily lives. They were explicitly asked to exclude weeks that included holidays, visits, or other special events. Participants completed their first set of questionnaires at the initial meeting with researchers in the lab. They received instructions on how to complete the momentary questionnaires on the palmtop computer, and all items were explained in detail. Couples were instructed not to talk about their reports during the study to minimize mutual influences while answering. The 7-day ambulatory assessment period took place between the first and the second meeting. At a second meeting, participants completed another set of questionnaires and took part in a short interview about their experience with the ambulatory assessment; these data were not used in this study. 
The equivalent of US\$100 was paid to each couple after the completion of the 6-month follow-up questionnaire (not analyzed in the present study).

Ambulatory assessment. The palmtop computers given to participants were programmed to ring four times a day, simultaneously for both partners, around 9:00 a.m., 1:00 p.m., 5:00 p.m., and 9:00 p.m., for seven consecutive days. The ringing times were randomly selected to be within approximately $30 \mathrm{~min}$ of the noted times to reduce expectancy effects. In total, each person reported their answers on 28 occasions ("momentary questionnaire"). As this study was part of a larger project on interpersonal emotion regulation, more variables measuring other concepts concerning emotion regulation and couple processes were assessed. After reporting on their own momentary affective valence and a list of intrapersonal emotion regulation strategies, participants also rated their partner's current affect. Then, they indicated how they dealt with their partner's affect by rating different interpersonal emotion regulation strategies, which included positive humor (see the following). These additional interpersonal strategies are not the focus of this study, but some have been investigated elsewhere (see Debrot, Cook, Perrez, \& Horn, 2012; Debrot et al., 2013; Debrot, Schoebi, Perrez, \& Horn, 2014). Participants had $2 \mathrm{hr}$ to respond to the momentary questionnaire after the ringtone signal. After this time, the questionnaire automatically closed. Completion rates for the momentary questionnaires were very good, at a rate of 91.4\%. The mean answering time after the ringtone was 9:03 min.

\section{Measures}

Daily positive humor in the couple. At the beginning of each momentary questionnaire, we assessed whether the couple had any kind of verbal contact (i.e., direct, phone, text message, e-mail, etc.) since the completion of the last momentary questionnaire. This was the case in $71.2 \%$ of all entries. If any contact was reported, a list of interpersonal emotion regulation strategies was displayed, and the participants were instructed to report how they dealt with their partner's affective state. The list included positive humor in the couple as a single item I tried to bring in good humor. To guarantee a common understanding of "good humor" as being benign, benevolent, and positive in nature, participants had been instructed in the first lab session that this referred to "anything that makes one laugh and/or could be perceived as comical." Examples of benevolent and positive versus negative humor were given and discussed with the participants. Over the assessment week, participants yielded average humor scores ranging from 0 to 3.71 $(M=1.1, S D=.8)$.

Momentary affect. At each measurement occasion, momentary affect was assessed. Participants were asked How do you feel at this moment? and were instructed to answer by means of two bipolar scales, ranging from $1=$ well to $9=$ unwell and from $1=$ discontent to $9=$ content. The first scale was reversed and the mean of the two scales was used, with higher values reflecting a more positive valence. This ambulatory assessment measure has been shown to have satisfactory psychometric properties (Wilhelm \& Schoebi, 2007). Over the assessment week, the average levels of momentary affective valence ranged from 3.74 to $8.61(M=6.55, S D=.87)$. 
Psychological intimacy. The questionnaire included the following questions, aiming to assess psychological intimacy: How have you been feeling regarding your partner (since the last data entry)? Responses were rated on a 5-point scale $(0=$ does not apply to $4=$ applies very strongly), using the following four items: cared for, close to, understood, and secure. The four ratings were averaged to yield a score of psychological intimacy. A confirmatory factor analysis indicated good psychometric properties for the scale (Debrot et al., 2012). The aggregated mean of each score within participants varied between 0.8 and 4.00, with an average score of $M=3.05(S D=.60)$, reflecting high daily levels of intimacy in this sample.

\section{Statistical model}

In the data set, momentary questionnaires were nested within persons and each person belonged to a couple. As recommended for multilevel analysis of intensive longitudinal data of distinguishable dyads (Bolger \& Laurenceau, 2013; Raudenbush, Brennan, \& Barnett, 1995) for testing H1 and H2, two-level Actor Partner Interdepence Models (APIMs) with two intercepts - one for the female and one for the male partner-were used (Kenny et al., 2006). Both intercepts were allowed to vary at the couple (level 2) and the occasion level (level 1). The parameter estimates for the actor and partner effects of interest were allowed to vary at the occasion level (level 1). All predictor variables were centered at the couple level so that the estimates reflect deviations from the average value within the couple. In addition, we controlled for the measure of the dependent variable at the previous occasion, so that the outcome reflected residualized change since the preceding report and controls for possible autocorrelations of the dependent variables over time. Furthermore, the individual mean of humor over the assessment period was added to the models. This allowed us to control for the effect of the person's general tendencies to use humor and to partial out between-person differences. Originally, we controlled for momentary questionnaire number and momentary questionnaire number squared to control for systematic linear or quadratic effects of time during the assessment period (e.g., that the momentary questionnaires in the beginning differ from those at the end). As these effects were not significant, we omitted them to simplify the equation. As described here, H1 was tested with momentary affect as the dependent variable, and $\mathrm{H} 2$ was the parallel model with intimacy as the dependent variable. Additionally, for a preliminary analysis aiming at exploring the variability of positive humor in the couple in daily life, an empty model with only female and male intercept was analyzed. We computed an effect size $r$ (Rosenthal, Rosnow, \& Rubin, 2003) based on the Wald test with the between-person standard deviation as reference. There is currently no dominating consent as how to compute effect sizes in multilevel modeling (Feingold, 2009), and therefore, these values should be interpreted with caution. The multilevel model was fitted with the MLwiN software Version 2.22 (Rabash, Steele, Brown, \& Goldstein, 2009).

To test the mediation hypothesis (H3), the Monte Carlo Method for Assessing Multilevel Mediation was applied (Preacher \& Selig, 2012). This method offers confidence intervals for the statistical testing of the indirect mediation paths in multilevel models. Two different paths were analyzed-the actor mediation path describes the indirect 
Table I. Mean and standard deviation of male and female partner's over all occasions averaged scores and their correlations (Pearson's $r$ ).

\begin{tabular}{|c|c|c|c|c|c|c|c|}
\hline \multirow[b]{2}{*}{ Measure } & \multicolumn{2}{|c|}{ Female } & \multicolumn{2}{|c|}{ Male } & \multirow[b]{2}{*}{1} & \multirow[b]{2}{*}{2} & \multirow[b]{2}{*}{3} \\
\hline & $M$ & $S D$ & $M$ & $S D$ & & & \\
\hline I. Momentary affect & 6.45 & .84 & 6.19 & .87 & - & .14 & $.3^{* *}$ \\
\hline 2. Positive humor & 1.24 & .85 & 0.98 & .73 & $.33^{* *}$ & - & .16 \\
\hline 3. Psychological intimacy & 3.05 & .60 & 3.05 & .61 & $.4 I^{* *}$ & $.24 *$ & - \\
\hline
\end{tabular}

Note. Correlations of female partners are presented above the diagonal $(N=102)$, and correlations of male partners $(N=102)$ are presented below the diagonal. Momentary affect, positive humor, and psychological intimacy are averaged at the person level over all 28 measurement occasions.

$* p<.05 ; * * p<.01 ; * * * p<.001$.

effect of humor on own affect via own intimacy (see Figure $1 ; a_{\mathrm{am}}-b_{\mathrm{am}} / a_{\mathrm{af}}-b_{\mathrm{af}}$ ). The partner mediation path reflected the indirect effect of humor on the partner's affect as mediated by the partner's intimacy (see Figure $1 ; a_{\mathrm{pm}}-b_{\mathrm{am}} / a_{\mathrm{pf}}-b_{\mathrm{af}}$ ). Both paths were tested separately for female and male partners. If zero was to fall outside the $95 \%$ confidence interval, the null hypothesis of no mediation would be rejected. For assessing the significance of the indirect paths of the mediation analysis, following the recommended procedure of Bauer, Preacher, and Gil (2006), a multivariate model was computed simultaneously testing two equations: The first equation tested the association of the mediator, intimacy, with the outcome, momentary affect. The second equation tested the association of humor and the mediator variable, intimacy, both predicting momentary affect.

\section{Results}

Table 1 presents the means, standard deviations, and correlation coefficients of the aggregated means on person level (i.e., summing up the 28 measurement occasions per person and dividing it by 28 ).

\section{Preliminary analysis: Variability of daily humor}

In a first step, within-person variability of humor was examined. For that purpose, an empty multilevel model with two intercepts, one for the female and one for the male partner, and humor as the dependent variable was conducted. Fixed effects of reported production of positive humor revealed that the average score in females was $b=0.98$ (female intercept, $S E=.07$ ) and in males $b=1.23$ (male intercept, $S E=.08$ ). The gender difference between average humor use in daily life was not significant $\chi^{2}(1)=$ $2.28 ; p=.12$. The random effects of the empty model revealed that the within-person variability over the occasions of the assessment week at level 1 was statistically significant within female $\left(\sigma_{\mathrm{ef}}^{2}=1.22 ; S E=.04\right)$ as well as within male partners $\left(\sigma_{\mathrm{em}}^{2}=\right.$ 1.13; $S E=.04)$. Furthermore, at level 2, there was also significant - though lowervariance between the female $\left(\sigma_{\mathrm{uf}}^{2}=.46 ; S E=.07\right)$ and male $\left(\sigma_{\mathrm{um}}^{2}=.64 ; S E=.1\right)$ 
participants within the couples. Additionally, level-2 humor covaried significantly between male and female partners $\left(\sigma_{\mathrm{fm}}=.16 ; S E=.06 ; p=.03\right)$. Taken together, these results suggest that the use of daily humor varies significantly within and between individuals with a significant interdependency between the partners.

\section{Actor and partner effects of daily humor}

HI: Actor and partner effects of humor on affect. The results of the first multilevel analysis testing the association between humor and momentary affect are displayed in the lefthand section of Table 2. For both partners, the report of having used positive humor in the relationship since the last momentary questionnaire was associated with a significant increase in the valence of own momentary affect. In addition, the use of positive humor was also associated with an increase in the partners' affective valence. In other words, during the day, when the partner produced positive humor expressed toward the romantic counterpart, the experience of positive affective valence of both partners increased. Thus, as expected in H1, actor and partner effects of production of positive humor on changes of momentary affect during the day emerged. The average individual level of humor use in daily life was controlled in Model 1; it was not significantly associated with momentary affect. All actor and partner effects did not differ significantly between male and female partners, all $\chi^{2} \operatorname{diff}_{(1)}$ between 0.93 and 2.18 , n.s., except for the association between the average individual level of humor and affect that was marginally different between men and women, $\chi^{2} \operatorname{diff}_{(1)}=3.79, p<.10$.

H2: Actor and partner effects of humor on intimacy. The second model testing actor and partner effects of positive humor on psychological intimacy is depicted in the right-hand side of Table 2. The intercepts around 3.3 suggest a high level of intimacy for the average couple (predictors are couple centered), as the possible scores range from 0 to 4 . Random effects revealed significant variability of intimacy within individual and between couples. Confirming our second hypothesis, positive humor predicted changes in own psychological intimacy in both female and male partners. Beyond that, there was a significant effect of humor on the partner's reported intimacy score. Again, these effects occurred above and beyond the individual mean use of humor, which did not significantly predict intimacy. Thus, the expectation that own and partner displays of humor would be associated with actor and partner fluctuations of psychological intimacy during daily life is supported. All associations were equal across gender, all $\chi^{2} \operatorname{diff}_{(1)}$ between .0 .001 and 2.24, n.s., except for the association between the daily actor humor and intimacy, that was significantly stronger in women than in men, $\chi^{2} \operatorname{diff}_{(1)}=6.04, p<.05$.

H3: Testing indirect paths humor-intimacy — affect. The MCAMM technique was used to test the mediational effect of intimacy. The indirect actor paths of humor via own intimacy on own momentary affect were not significant in both female $(95 \%$ $\left.\mathrm{CI}_{\text {female actors }}[-.2, .03]\right)$ and male partners $\left(95 \% \mathrm{CI}_{\text {male actors }}[-.2, .04]\right)$. However, the indirect partner paths were significant. Humor reported by women showed significant associations with their male partner's affect via male intimacy $\left(95 \% \mathrm{CI}_{\text {female partners }}\right.$ 


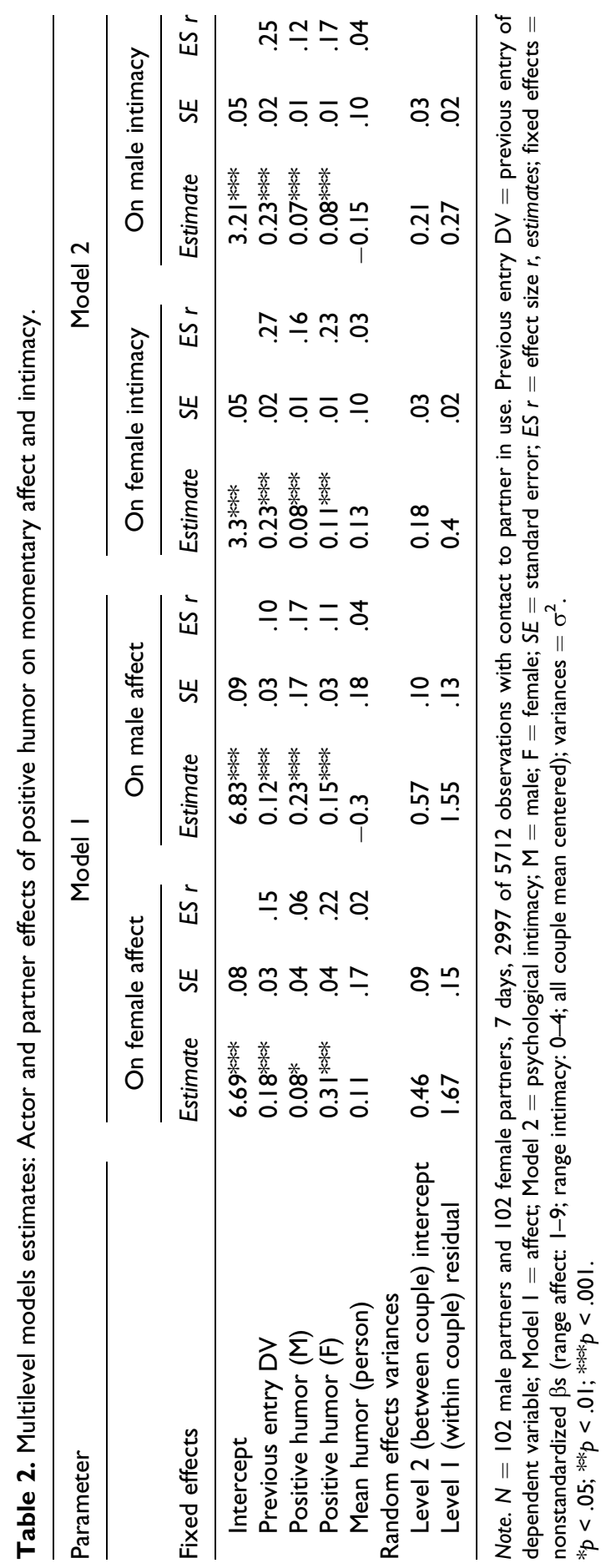


$[.03, .07])$. Additionally, the indirect effect of male humor on female affect via female intimacy was also significant $\left(95 \% \mathrm{CI}_{\text {male partners }}[.08, .32]\right)$.

\section{Discussion}

This ambulatory assessment study aimed to investigate intra- and interpersonal effects of positive humor on changes in momentary affect among romantic partners in an everyday life context. In accordance with an interpersonal perspective on emotion regulation, we hypothesized that changes in daily affect as a consequence of relational humor would be mediated by changes in psychological intimacy.

$\mathrm{H} 1$ posited that positive humor is associated with changes in positive momentary affect across different situations in both the individual and their romantic partner. Our first hypothesis was supported by the multilevel APIM, which showed that in the hours after the report of having displayed positive humor, the valence of the affective state increased. This indicates that not only the partner, who is the target of the humor display benefits from the humor, but also the person performing this humorous interaction also benefits from the humor display. The partner's use of humor was associated with intrapersonal increases in momentary well-being, above and beyond this association. In general, effects were small to moderate and did not differ significantly between men and women.

As a next step, our second hypothesis (H2) that there are actor and partner effects of positive humor on psychological intimacy was also supported. In couples' daily lives, positive humor displayed by the partner was associated with increased feelings of intimacy in themselves as well as in their romantic counterpart. The actor effect of humor on own momentary intimacy was significantly more pronounced in women than in male partners, even though this effect was statistically significant in both genders. In other words, in daily life, positive humor displayed with the purpose to deal with the partners' mood is more closely associated with feeling closer to the partner in females than in males. Those results are in line with findings of a dyadic study that showed significant actor effects of positive relational humor on relationship satisfaction in wives alone (De Koning \& Weiss, 2002). According to Reis and Shaver's (1988) process model, the establishment of psychological intimacy is a function of disclosure followed by a responsive reaction of the interaction partner. In general, women tend to disclose more than men also in interactions within romantic relationships (Dindia \& Allen, 1992). Further research is needed to investigate whether positive humor targeting the partner might involve more disclosure by the female counterpart, and thus leads to a greater perceived intimacy depending on the level of disclosure involved.

Furthermore, the assumption of $\mathrm{H} 3$, that is, a socio-affective pathway in interpersonal emotion regulation, was confirmed: Intimacy partially mediated the effects of humor on affect. This means that changes in partners' mood associated with positive humor of the counterpart were explained by increased feelings of shared psychological intimacy. The partial mediation does not exclude other working mechanisms - shared amusement and laughter might be further mechanisms worthwhile to investigate in this context (Kurtz \& Algoe, 2015). 
The mediation was only significant for the associations with the partner's affective state (see Figure 1 path $a_{\mathrm{PM}}-b_{\mathrm{AM}} / a_{\mathrm{PF}}-b_{\mathrm{AF}}$ ) but not for one's own. In other words, the actor effect of positive humor was not mediated by psychological intimacy. This suggests that there may be different within-person processes compared to interpersonal processes crossing over between partners. Within-person engaging in a positive strategy like humor seems to provoke positive changes in affective states that are not explained by altered relationship quality - even though the use of humor was also related to positive changes in psychological intimacy within individuals. However, the observed changes in intimacy did not explain the more positive affective state. Even if it is produced in a relational context and aimed at regulating the partner's mood, this suggests that the known emotion regulatory mechanisms of humor within the person such as reappraisal (Samson \& Gross, 2014) might be more essential for the effects within the individual performing the humor. Another possibility is that the attempt to deal with the partner's mood in a positive way is a compassionate act that improves the person's mood independently of changes in intimacy. Indeed, similar positive effects of relationshipenhancing, "giving" acts have been reported in the literature (Reis, Maniaci, \& Rogge, 2017). Moreover, when the partner's mood is negative, this extrinsic form of interpersonal emotion regulation might be perceived as stressful for the actor. A further suggested link between humor and well-being is that it buffers negative stress effects and fosters mastery (Martin \& Lefcourt, 1983). Further research is needed to explore possible moderating effects of situational aspects like the intensity and negativity of the partner's mood and stress levels of the individual displaying humor.

In summary, for the partner displaying humor, the emotion regulatory pathway of humor seems to be intrapersonal as it is not related to the observed changes in intimacy. In contrast, for the target of their humor, changes in intimacy mediate the improvement of mood. This supports the notion of a socio-affective pathway on mood via changes in relationship quality. In other words, emotion regulation can happen via changes in relationship quality (Debrot et al., 2013). However, this was a partial mediation, which indicates that changes in intimacy played a significant but not exclusive role. Furthermore, it should be considered that the use of positive humor was explicitly assessed in the context of interpersonal emotion regulation (i.e., the attempt to deal with the partner's emotions); thus, we do not know whether comparable results would be found when humor is not targeted at dealing with a partner's affective state. Further research is needed to shed more light on the interplay of intra- and interpersonal mechanisms of daily humor which regulate emotions in a relational context.

\section{Limitations and outlook}

This study is the first to demonstrate a socio-affective pathway of positive humor on mood in romantic partners' daily lives. However, despite its strengths, the study design has a few limitations. First, although the temporal unfolding of the study is addressed by controlling for prior levels of humor and affect, the nonexperimental context of the study does not allow for firm causal interpretations. Further research is necessary to explore the causal mechanisms between positive humor, relationship quality, and emotions. For example, randomized controlled ecological momentary interventions (Heron \& Smyth, 
2010) on positive humor in daily life could be used to experimentally manipulate the situation in an ecologically valid way. Furthermore, another limitation of the current study, very common in intensive longitudinal research designs, is that humor was assessed with a single item, and contextual aspects were not included. Thus, we could not assess the reliability of the measure nor could we investigate whether different contexts would influence the present results. However, as the question was explicitly addressing positive forms of humor in couples, the results are coherent with earlier research underlining the difference between positive or benign and negative, malign, or sarcastic humor. Further research investigating potential differences of the effect of humor in the relationship according to contexts or content of humor use in couples' everyday life seems intriguing. Considering the significant partner effects, a shared nature of the humor production can be assumed. However, the current design does not allow us to make inferences about the quality of the shared experience of the humor. Further research including measures of shared amusement and laughter in daily life would be important for shedding more light on this issue. Audio sensing of shared laughter during the day as applied in the method of the Electronically Activated Recorder (Mehl, Robbins, \& Deters, 2012) in combination with daily self-reports of positive humor would be a powerful way of improving our understanding how the use of humor relates to the partners' well-being. Finally, the study was conducted relying on a quite homogenous sample of highly satisfied romantic couples. Generalizing the findings to less satisfied couples and other close relationships is premature and needs further investigation.

The present study opens the door for further research in this field. It would be interesting to know more about the situational context of the humor display. In our study, our measures of humor showed associations with affective state and relationship quality across the multiplicity of situations in daily life. Considering the abundance of situational features in daily life that are influencing fluctuations in momentary affect, the fact that positive humor in the relationship provokes significant effects encourages the assumption that the reported associations reflect fundamental processes of high relevance in interpersonal emotion regulation.

In future studies, the perception of humor by the partner, that is, if a humorous act was perceived as funny by the partner, would be a further interesting line of inquiry (see Kurtz \& Algeo, 2015). The concept of "shared humor," that is, how partners cocreate humorous situations and perception, appears to be of interest as well (see Hall, 2017), especially regarding intimacy and relationship quality. Furthermore, the similarity of humor style (Barelds \& Barelds-Dijkstra, 2010) and humor orientation in dyads has been shown to be relevant for the relational effects of humor. So far, this has been studied as a stable trait. Accordingly, another possible area of future research would be to investigate whether the changing context in daily life leads to fluctuations in these similarities and their outcomes.

Despite the limitations presented earlier, the dyadic ambulatory assessment procedure of this study has several strengths. First, compared to questionnaires or laboratory data, the assessment occurred in participants' real life setting on a daily basis, increasing ecological validity. It further minimizes retrospection bias and reduces effects of motivated and biased social perception (Fahrenberg, Myrtek, Pawlik, \& Perrez, 2007; Mehl \& Conner, 2012; Perrez, Schoebi, \& Wilhelm, 2000). The dyadic assessment 
allowed the inclusion of both partner's perspectives and the examination of partner effects, which, to the best of authors' knowledge, had never been done to investigate humor in daily life. Finally, the multiple assessment occasions provided a reliable sample of the studied behavior.

\section{Conclusion}

What can we say about positive humor in couples' everyday lives? Individuals rely on humor in daily life and they vary across situations in the tendency to do so. Couples' engagement in humor seems to be immediately associated with their own and their partner's positive affective valence, as well as experienced intimacy. The present dyadic ambulatory assessment design included four data entries per day, allowing a fine-grained analysis of the temporal unfolding of the effect of daily humor within-person and withincouple in a naturalistic context (Reis, 2012). Furthermore, our analyses allowed us to rule out that positive humor in the couple was a mere epiphenomenon of earlier positive affect, as this was controlled for in the models. The results indicate an immediate association of humor and daily affect within-person and support the view of positive humor as an adaptive emotion regulation strategy (Lefcourt et al., 1995; Samson \& Gross, 2014; Vaillant, 2000). Pressman and Cohen (2005) suggest that the measure of momentary affect is a particularly powerful predictor of health more than retrospective measures which reflect more dispositional affective traits. Our study therefore contributes to the research on daily health processes by pointing to the importance of positive humor as an interpersonal emotion regulation strategy.

Positive humor has intra- and interpersonal benefits: It is used as an emotion regulation strategy by the individual and seems to be beneficial for maintaining a healthy relationship. As one might benefit from one's own positive humor as well as from the partner's humor, this seems to be a particularly low-cost and enjoyable emotion regulation strategy. Indeed, social regulation of emotion in general is seen as less effortful (Coan \& Sbarra, 2015). In situations in which individual resources are challenged, the co-regulating partner's humor might be a valuable resource for emotion regulation.

Daily humor has strong interpersonal correlates and significant positive partner and relationship effects. Humor can be seen as an interpersonal emotion regulation strategy and might represent an important gateway to socio-affective pathways to health. The remarkable partner effects in our study hint toward possible clinical implications and speak in favor of considering the training of positive humor in relationships as an adaptive emotion regulation strategy.

\section{Acknowledgements}

The authors would like to acknowledge Louella Molina and Manuela Christen for their support in data collection, Dominik Schoebi for the valuable and appreciated support regarding the data analysis, Ian Law and Karl Bühler for the technical support, Rita Hitching for proof reading an earlier version of the manuscript as well as Jessica Maxwell and Aikaterini Giannadou for a more current one. Distinct aspects of this project have been published elsewhere. 


\section{Funding}

The author(s) disclosed receipt of the following financial support for the research, authorship, and/ or publication of this article: The research was supported by a Swiss National Science Foundation grant as project 5 "Intra- and interpersonal emotion regulation in couples" in the National Centre of Competence in Research "Affective Science" awarded to the last author and Michael Reicherts, both University of Fribourg. The first and third author received fellowships within this project, the third author completed her doctoral dissertation as part of this funding project. The second author was supported by the Swiss National Science Foundation with Fellowships for Prospective and Advanced Researchers and the Ambizione Fellowship. Currently, the first author is supported by a Swiss National Science Foundation Marie-Heim-Voegtlin Fellowship (PMPDP1_164470).

\section{ORCID iD}

Andrea B. Horn (D) http://orcid.org/0000-0003-2729-7062

\section{Open research statement}

This research was not pre-registered. The data and materials used in the research are available upon request by emailing a.horn@psychologie.uzh.ch.

\section{References}

Barelds, D. P. H., \& Barelds-Dijkstra, P. (2010). Humor in intimate relationships: Ties among sense of humor, similarity in humor and relationship quality. Humor: International Journal of Humor Research, 23, 447-465. doi:10.1515/humr.2010.021

Bauer, D. J., Preacher, K. J., \& Gil, K. M. (2006). Conceptualizing and testing random indirect effects and moderated mediation in multilevel models: New procedures and recommendations. Psychological Methods, 11, 142-163. doi:10.1037/1082-989X.11.2.142

Bolger, N., \& Laurenceau, J. P. (2013). Intensive longitudinal methods: An introduction to diary and experience sampling research. New York, NY: Guilford Press.

Bolger, N., Stadler, G., \& Laurenceau, J. P. (2012). Power analysis for intensive longitudinal studies. In M. M. R. \& C. T. S. (Eds.), Handbook of Research Methods for Studying Daily Life (pp. 285-301). New York, NY: Guilford Press.

Booth-Butterfield, M., Wanzer, M. B., Weil, N., \& Krezmien, E. (2014). Communication of humor during bereavement: Intrapersonal and interpersonal emotion management strategies. Communication Quarterly, 62, 436-454. doi:10.1080/01463373.2014.922487

Caird, S., \& Martin, R. A. (2014). Relationship-focused humor styles and relationship satisfaction in dating couples: A repeated-measures design. Humor: International Journal of Humor Research, 27, 227-247. doi:10.1515/humor-2014-0015

Campbell, L., Martin, R. A., \& Ward, J. R. (2008). An observational study of humor use while resolving conflict in dating couples. Personal Relationships, 15, 41-55. doi:10.1111/ j.1475-6811.2007.00183.x

Cann, A., Zapata, C. L., \& Davis, H. B. (2009). Positive and negative styles of humor in communication: Evidence for the importance of considering both styles. Communication Quarterly, 57, 452-468. doi:10.1080/01463370903313398

Coan, J. A., Beckes, L., Gonzalez, M. Z., Maresh, E. L., Brown, C. L., \& Hasselmo, K. (2017). Relationship status and perceived support in the social regulation of neural responses to threat. Social Cognitive and Affective Neuroscience, 12, 1574-1583. doi:10.1093/scan/nsx091 
Coan, J. A., \& Sbarra, D. A. (2015). Social baseline theory: The social regulation of risk and effort. Current Opinion in Psychology, 1, 87-91. doi:10.1016/j.copsyc.2014.12.021

Coan, J. A., Schaefer, H. S., \& Davidson, R. J. (2006). Lending a hand: Social regulation of the neural response to threat. Psychological Science, 17, 1032-1039. doi:10.1111/j.1467-9280. 2006.01832.x

De Koning, E., \& Weiss, R. L. (2002). The relational humor inventory: Functions of humor in close relationships. The American Journal of Family Therapy, 30, 1-18. doi:10.1080/ 019261802753455615

Debrot, A., Cook, W. L., Perrez, M., \& Horn, A. B. (2012). Deeds matter: Daily enacted responsiveness and intimacy in couples' daily lives. Journal of Family Psychology, 26, 617-627. doi:10.1037/a0028666

Debrot, A., Schoebi, D., Perrez, M., \& Horn, A. B. (2013). Touch as an interpersonal emotion regulation process in couples' daily lives: The mediating role of psychological intimacy. Personality \& Social Psychology Bulletin, 39, 1373-1385. doi:10.1177/0146167213497592

Debrot, A., Schoebi, D., Perrez, M., \& Horn, A. B. (2014). Stroking your beloved one's white bear: Responsive touch by the romantic partner buffers the negative effect of thought suppression on daily mood. Journal of Social and Clinical Psychology, 33, 75-97. doi:10.1521/jscp.2014.33.1.75

Dindia, K., \& Allen, M. (1992). Sex differences in self-disclosure: A meta-analysis. Psychological Bulletin, 112, 106-124. doi:10.1037/0033-2909.112.1.106

Dinkel, A., \& Balck, F. (2005). An evaluation of the German Relationship Assessment Scale. Swiss Journal of Psychology, 64, 259-263. doi:10.1024/1421-0185.64.4.259

Fahrenberg, J., Myrtek, M., Pawlik, K., \& Perrez, M. (2007). Ambulatory assessment-monitoring behavior in daily life settings: A behavioral-scientific challenge for psychology. European Journal of Psychological Assessment, 23, 206-213. doi:10.1027/1015-5759.23.4.206

Feingold, A. (2009). Effect sizes for growth-modeling analysis for controlled clinical trials in the same metric as for classical analysis. Psychological methods, 14, 43. doi:10.1037/a0014699

Fraley, B., \& Aron, A. (2004). The effect of a shared humorous experience on closeness in initial encounters. Personal Relationships, 11, 61-78. doi:10.1111/j.1475-6811.2004.00071.x

Fredrickson, B. L., \& Levenson, R. W. (1998). Positive emotions speed recovery from the cardiovascular sequelae of negative emotions. Cognition \& Emotion, 12, 191-220. doi:10.1080/ 026999398379718

Freud, S. (1928). Humour. International Journal of Psychoanalysis, 9, 1-6.

Goldin, P. R., McRae, K., Ramel, W., \& Gross, J. J. (2008). The neural bases of emotion regulation: Reappraisal and suppression of negative emotion. Biological Psychiatry, 63, 577-586. doi:10.1016/j.biopsych.2007.05.031

Gross, J. J., \& Thompson, R. A. (2007). Emotion regulation: Conceptual foundations. In J. Gross (Ed.), Handbook of emotion regulation (pp. 3-24). New York, NY: Guilford Press.

Hall, J. A. (2013). Humor in long-term romantic relationships: The association of general humor styles and relationship-specific functions with relationship satisfaction. Western Journal of Communication, 77, 272-292. doi:10.1080/10570314.2012.757796

Hall, J. A. (2017). Humor in romantic relationships: A meta-analysis. Personal Relationships, 24 , 306-322. doi: $10.1111 /$ pere. 12183

Hendrick, S. S., Dicke, A., \& Hendrick, C. (1998). The relationship assessment scale. Journal of Social and Personal Relationships, 15, 137-142. doi:10.1177/0265407598151009 
Heron, K. E., \& Smyth, J. M. (2010). Ecological momentary interventions: Incorporating mobile technology into psychosocial and health behaviour treatments. British Journal of Health Psychology, 15, 1-39. doi:10.1348/135910709X466063

Holt-Lunstad, J., \& Smith, T. B. (2012). Social relationships and mortality. Social and Personality Psychology Compass, 6, 41-53. doi:10.1111/j.1751-9004.2011.00406.x

Holt-Lunstad, J., Smith, T. B., Baker, M., Harris, T., \& Stephenson, D. (2015). Loneliness and social isolation as risk factors for mortality: A meta-analytic review. Perspectives on Psychological Science, 10, 227-237. doi:10.1177/1745691614568352

Horn, A. B., \& Maercker, A. (2016). Intra- and interpersonal emotion regulation and adjustment symptoms in couples: The role of co-brooding and co-reappraisal. [journal article]. BMC Psychology, 4, 51. doi:10.1186/s40359-016-0159-7

Howland, M., \& Simpson, J. A. (2014). Attachment orientations and reactivity to humor in a social support context. Journal of Social and Personal Relationships, 31, 114-137. doi:10.1177/ 0265407513488016

Kashdan, T. B., Yarbro, J., McKnight, P. E., \& Nezlek, J. B. (2014). Laughter with someone else leads to future social rewards: Temporal change using experience sampling methodology. Personality and Individual Differences, 58, 15-19. doi:10.1016/j.paid.2013.09.025

Kenny, D. A., Kashy, D. A., \& Cook, W. L. (2006). Methodology in the social sciences. In D. A. Kenny (Ed.), Dyadic data analysis. New York, NY: Guilford Press.

Kok, B. E., Coffey, K. A., Cohn, M. A., Catalino, L. I., Vacharkulksemsuk, T., Algoe, S. B., \& Fredrickson, B. L. (2013). How positive emotions build physical health: Perceived positive social connections account for the upward spiral between positive emotions and vagal tone. Psychological Science, 24, 1123-1132. doi:10.1177/0956797612470827

Kugler, L., \& Kuhbandner, C. (2015). That's not funny!-But it should be: Effects of humorous emotion regulation on emotional experience and memory. Frontiers in Psychology, 6, 1296. doi:0.3389/fpsyg.2015.01296

Kurtz, L. E., \& Algoe, S. B. (2015). Putting laughter in context: Shared laughter as behavioral indicator of relationship well-being. Personal Relationships, 22, 573-590. doi:10.1111/pere. 12095

Lauer, R. H., Lauer, J. C., \& Kerr, S. T. (1990). The long-term marriage: Perceptions of stability and satisfaction. The International Journal of Aging and Human Development, 31, 189-195. doi:10.2190/h4x7-9dvx-w2n1-d3bf

Lefcourt, H. M., Davidson, K., Shepherd, R., Phillips, M., Prkachin, K., \& Mills, D. (1995). Perspective-taking humor: Accounting for stress moderation. Journal of Social and Clinical Psychology, 14, 373-391. doi:10.1521/jscp.1995.14.4.373

Maas, C. J. M., \& Hox, J. J. (2005). Sufficient sample sizes for multilevel modeling. Methodology, 1, 86-92. doi:10.1027/1614-2241.1.3.86

Maiolino, N., \& Kuiper, N. (2016). Examining the impact of a brief humor exercise on psychological well-being. Translational Issues in Psychological Science, 2, 4-13. doi:10.1037/ tps0000065

Martin, R. A. (2002). Is laughter the best medicine? Humor, laughter, and physical health. Current Directions in Psychological Science, 11, 216-220. doi:10.1111/1467-8721.00204

Martin, R. A. (2004). Sense of humor and physical health: Theoretical issues, recent findings, and future directions. Humor: International Journal of Humor Research, 17, 1-20. doi:10.1515/ humr.2004.005. 
Martin, R. A., \& Lefcourt, H. M. (1983). Sense of humor as a moderator of the relation between stressors and moods. Journal of Personality and Social Psychology, 45, 1313-1324. doi:10.1037/0022-3514.45.6.1313

Martin, R. A., Puhlik-Doris, P., Larsen, G., Gray, J., \& Weir, K. (2003). Individual differences in uses of humor and their relation to psychological well-being: Development of the Humor Styles Questionnaire. Journal of Research in Personality, 37, 48-75. doi:10.1016/ s0092-6566(02)00534-2

Mehl, M. R., \& Conner, T. S. (2012). Handbook of research methods for studying daily life. New York, NY: Guilford Press.

Mehl, M. R., Robbins, M. L., \& Deters, F. G. E. (2012). Naturalistic observation of health-relevant social processes: The electronically activated recorder methodology in psychosomatics. Psychosomatic Medicine, 74, 410-417. doi:10.1097/PSY.0b013e3182545470

Perrez, M., Schoebi, D., \& Wilhelm, P. (2000). How to assess social regulation of stress and emotions in daily family life? A computer-assisted family self-monitoring system (FASEM-C). Clinical Psychology \& Psychotherapy, 7, 326-339. doi:10.1002/1099-0879(200010)7:4<326:: AID-CPP266>3.0.CO;2-0

Pietromonaco, P. R., \& Collins, N. L. (2017). Interpersonal mechanisms linking close relationships to health. American Psychologist, 72, 531-542. doi:10.1037/amp0000129

Preacher, K. J., \& Selig, J. P. (2012). Advantages of monte carlo confidence intervals for indirect effects. Communication Methods and Measures, 6, 77-98. doi:10.1080/19312458.2012. 679848

Pressman, S. D., \& Cohen, S. (2005). Does positive affect influence health? Psychological Bulletin, 131, 925-971. doi:10.1037/0033-2909.131.6.925

Rabash, J., Steele, F., Brown, W. J., \& Goldstein, H. (2009). A user's guide to MLwiN, version 2.10 $(3 r d)$. Bristol, England: University of Bristol Center for Multilevel Modelling.

Raudenbush, S., Brennan, R., \& Barnett, R. (1995). A multivariate hierarchical model for studying psychological change within married couples. Journal of Family Psychology, 9, 161-174.

Reis, H. T. (2012). Why researchers should think "real-world": A conceptual rationale. In M. R. Mehl \& T. S. Conner (Eds.), Handbook of research methods for studying daily life (pp. 3-21). New York, NY: Guilford Press.

Reis, H. T., Maniaci, M. R., \& Rogge, R. D. (2017). Compassionate acts and everyday emotional well-being among newlyweds. Emotion, 17, 751-763. doi:10.1037/emo0000281

Reis, H. T., \& Shaver, P. (1988). Intimacy as an interpersonal process. In S. Duck, D. F. Hay, S. E. Hobfoll, W. Ickes, \& B. M. Montgomery (Eds.), Handbook of personal relationships: Theory, research and interventions (pp. 367-389). Oxford, England: John Wiley \& Sons.

Rime, B. (2007). Interpersonal emotion regulation. In J. J. Gross (Ed.), Handbook of emotion regulation. New York, NY: Guilford Press.

Rosenthal, R., Rosnow, R., \& Rubin, D. (2003). Contrasts and effect sizes in behavioral research: A correlational approach. Cambridge, UK: Cambridge University Press.

Samson, A. C., Glassco, A. L., Lee, I. A., \& Gross, J. J. (2014). Humorous coping and serious reappraisal: Short-term and longer-term effects. Europe's Journal of Psychology, 10, 571-581. doi:10.5964/ejop.v10i3.730

Samson, A. C., \& Gross, J. J. (2012). Humour as emotion regulation: The differential consequences of negative versus positive humour. Cognition and Emotion, 26, 375-384. doi:10.1080/02699931.2011.585069 
Samson, A. C., \& Gross, J. J. (2014). The dark and light sides of humor: An emotion-regulation perspective. In J. Gruber, J. T. Moskowitz, J. Gruber, \& J. T. Moskowitz (Eds.), Positive emotion: Integrating the light sides and dark sides (pp. 169-182). New York, NY: Oxford University Press.

Strick, M., Holland, R. W., van Baaren, R. B., \& Van Knippenberg, A. D. (2009). Finding comfort in a joke: Consolatory effects of humor through cognitive distraction. Emotion, 9, 574-578. doi:10.1037/a0015951

Vaillant, G. E. (1992). The historical origins and future potential of sigmund freud's concept of the mechanisms of defence. International Review of Psycho-Analysis, 19, 35-50.

Vaillant, G. E. (2000). Adaptive mental mechanisms. Their role in a positive psychology. American Psychologist, 55, 89-98. doi:10.1037/0003-066X.55.1.89

Vela, L. E., Booth-Butterfield, M., Wanzer, M. B., \& Vallade, J. I. (2013). Relationships among humor, coping, relationship stress, and satisfaction in dating relationships: Replication and extension. Communication Research Reports, 30, 68-75. doi:10.1080/08824096.2012.746224

Wilhelm, P., \& Schoebi, D. (2007). Assessing mood in daily life: Structural validity, sensitivity to change, and reliability of a short-scale to measure three basic dimensions of mood. European Journal of Psychological Assessment, 23, 258. doi:10.1027/1015-5759.23.4.258

Winterheld, H. A., Simpson, J. A., \& Oriña, M. M. (2013). It's in the way that you use it: Attachment and the dyadic nature of humor during conflict negotiation in romantic couples. Personality and Social Psychology Bulletin, 39, 496-508. doi:10.1177/0146167213479133 